\title{
Measuring County Resilience After the 2008 Wenchuan Earthquake
}

\author{
Xiaolu $\mathrm{Li}^{1,2} \cdot$ Nina $\mathrm{Lam}^{2} \cdot$ Yi Qiang ${ }^{3} \cdot \operatorname{Kenan} \mathrm{Li}^{2}$. \\ Lirong Yin $^{4} \cdot$ Shan Liu ${ }^{1} \cdot$ Wenfeng Zheng ${ }^{1,2}$
}

Published online: 21 December 2016

(c) The Author(s) 2016. This article is published with open access at Springerlink.com

\begin{abstract}
The catastrophic earthquake that struck Sichuan Province, China, in 2008 caused serious damage to Wenchuan County and surrounding areas in southwestern China. In recent years, great attention has been paid to the resilience of the affected area. This study applied the resilience inference measurement (RIM) model to quantify and validate the community resilience of 105 counties in the impacted area. The RIM model uses cluster analysis to classify counties into four resilience levels according to the exposure, damage, and recovery conditions. The model then applies discriminant analysis to quantify the influence of socioeconomic characteristics on the county's resilience. Analysis results show that counties located at the epicenter had the lowest resilience, but counties immediately adjacent to the epicenter had the highest resilience capacities. Counties that were farther away from the epicenter returned to normal resiliency quickly. Socioeconomic variables_including sex ratio, per capita GDP, percent of ethnic minority, and medical facilities-were identified as the most influential characteristics influencing resilience. This study provides useful information to improve county resilience to earthquakes and support decision making for sustainable development.
\end{abstract}

Wenfeng Zheng

wenfeng.zheng.cn@gmail.com

1 School of Automation, University of Electronic Science and Technology of China, Chengdu 610054, Sichuan, China

2 Department of Environmental Sciences, Louisiana State University, Baton Rouge, LA 70803, USA

3 The Earth Lab, University of Colorado Boulder, Boulder, CO 80303, USA

4 Geographical \& Sustainability Sciences Department, University of Iowa, Iowa City, IA 52242, USA
Keywords China $\cdot$ Resilience $\cdot$ Resilience inference measurement (RIM) model · Vulnerability · Wenchuan earthquake

\section{Introduction}

Wenchuan County in Sichuan Province, China, and its surrounding counties are part of a region prone to frequent and destructive earthquakes and their accompanying secondary disasters (Chen et al. 2007; Li et al. 2016). The Wenchuan Earthquake, which occurred on 12 May 2008 is known for its huge destruction and high mortality. The magnitude 7.9 earthquake caused more than 69,227 deaths and property damages of over RMB 845.1 billion Yuan (Guo 2012). Due to the mountainous landscape, low economic development, and poor infrastructure, Wenchuan County and its surrounding regions are extremely vulnerable to earthquakes and secondary disasters such as landslides and barrier lake floods. Although these counties have similar characteristics in many aspects, observers noted that some counties experienced less damage during earthquakes and recovered more quickly afterwards (Guo 2012). Based on these observations, two questions are put forward: (1) are some counties more resilient to earthquakes than others; and (2) what socioeconomic characteristics make a county more resilient? The answers to these two questions could help improve the resilience of counties by promoting or controlling certain socioeconomic characteristics of an area.

Using the definition followed by a US National Research Council report (NRC 2012, p. 1), this study defines resilience of a community as "the ability to prepare and plan for, absorb, recover from, and more successfully 
adapt to adverse events over time." There is an extensive literature on definitions (Holling 1996), frameworks (Bruneau et al. 2003; Cutter et al. 2003), and case studies (Cutter et al. 2003, 2010; Boruff et al. 2005; Reams et al. 2012) of resilience. But with a few exceptions (for example, Fekete 2009; Tate 2012), studies that quantitatively measured resilience and were accompanied with validation are rare. The challenges of measuring community resilience to disaster are many. First, due to the diverse characteristics of disasters, complex natural and social processes, and varying definitions of the terms (Cutter et al. 2014), there is significant controversy on how to identify the main factors leading to resilience. Second, the many subjective factors and inaccurate weights assigned to variables make the measurement model difficult to generalize and apply to other contexts (Bruneau et al. 2003; NRC 2012). Third, studies that explored community resilience to seismic disasters have seldom been validated with empirical data (Bruneau et al. 2003; Chang and Shinozuka 2004).

To address some of these issues, Lam and her fellow researchers developed the resilience inference measurement (RIM) model to assess community resilience and to identify the key variables affecting resilience (Lam et al. 2015a). The RIM model has been applied in the Gulf of Mexico region to measure community resilience to coastal hazards (Lam et al. 2015a, b), and at different geographical scales in Louisiana (Li 2013). The RIM model is theoretically sound; it incorporates empirical validation and can be easily extended to study various disasters in different places (Lam et al. 2015a, b). The RIM framework is not confined to a specific type of disaster or indicators. Instead, it defines a general framework and methodology for measuring community resilience to different hazards. The RIM framework consists of three dimensions-exposure, damage, and recovery-and the two (dis)abilities-vulnerability and adaptability - that link the three dimensions. By selecting appropriate indicators to represent these three dimensions, the RIM framework can be transformed to measure community resilience in confronting various disasters in different places and to identify key variables that affect that resiliency. As discussed in detail in Sect. 3, the RIM model overcomes two major difficulties in assessing resilience: validation of the derived resilience index and statistical inference.

This study applies the RIM model to analyze quantitatively community resilience after the 2008 Wenchuan Earthquake. We focus on the quake-prone region in southwestern China, specifically the hardest-hit counties of Sichuan, Gansu, and Shaanxi Provinces affected by the 2008 Wenchuan Earthquake. In this region, earthquakes are an active hazard and can be tremendously destructive at fairly regular and frequent intervals. Therefore, it becomes essential to study community resilience to seismic disaster in this region. The Wenchuan Earthquake received great attention because of the massive damage and heavy casualties it caused. Yet studies on community resilience to seismic disasters in this region or in China are scarce. This study on community resilience to earthquakes in China intends to contribute to filling a gap in this research field. Due to the limitation on data availability, a total of 105 counties around the epicenter that had the most serious economic losses caused by the Wenchuan Earthquake were selected for this study.

\section{Related Work}

The term resilience is encountered in multiple disciplines ranging from engineering, psychology, environment, and sociology to geography and the humanities. The original definition of resilience from the Merriam-Webster online dictionary ${ }^{1}$ is "the capability of a strained body to recover its size and shape after deformation caused especially by compressive stress; an ability to recover from or adjust easily to misfortune or change". Holling (1996) defined resilience in two forms: engineering resilience, which refers to how fast the system returns to its original state after disturbance, and ecological resilience, which indicates how far the system can be perturbed without shifting to a different state. Adger et al. (2010) elaborated that resilience includes two elements: the ability to self-organize and the capacity to learn and adapt. Bruneau et al. (2003) suggested that a broad conceptualization of resilience should include the ability of a unit to reduce failure probabilities, consequences from failures, and time to recovery. They further defined resilience for both physical and social systems to consist of four properties: robustness, redundancy, resourcefulness, and rapidity (Bruneau and Reinhorn 2006). Recently, the concept of resilience is often mixed with other closely related concepts such as vulnerability, adaptability, and sustainability, making the measurement of resilience more complicated (Cutter et al. 2008; Lam et al. 2015a).

The different understandings of the resilience concept lead to various resilience measurements in many studies. The concept also varies when disaster occurs in different natural and socioeconomic environments, which makes it very difficult to define indicators that are universally applicable for resilience measurement. Cutter et al. (2003) developed the Social Vulnerability Index (SoVI) to assess social vulnerability to environmental hazards using countylevel socioeconomic and demographic data in the United States. The method produced 11 factors from 42 variables

\footnotetext{
${ }^{1}$ https://www.merriam-webster.com/dictionary/resilience.
} 
to explain $76.4 \%$ of variance based on factor analysis, and created SoVI scores using the factor scores for each county. Then Cutter et al. (2008) provided a local-scale resilience assessment theoretical framework, the disaster resilience of place (DROP) model. The study presented resilience as a continuous dynamic process influenced by both exposure and exogenous factors from social systems. Cutter et al. (2010) subsequently introduced another set of indicators to derive the Baseline Resilience Index for Communities (BRIC). Although the frameworks for vulnerability and resilience assessment as presented in these studies are comprehensive, the indices constructed via these approaches lacked empirical validation of variable selection and weighting. This shortcoming still exists in many studies on resilience measurement. Another group of researchers used observable outcomes directly, such as real damage and exposure data, to derive the indices. Lam et al. (2014) derived a vulnerability index to coastal hazards in the Caribbean countries, using real damage data to regress with a set of social and environmental variables. The regression coefficients were then used to determine the weight of each variable in the composite index. Lam et al. (2015a) also developed the resilience inference measurement (RIM) method for measuring community resilience to coastal hazards. The RIM method follows the rationale of using real observable outcomes to derive the index and employs two statistical procedures: $K$-means cluster analysis and discriminant analysis ( $\mathrm{Li}$ et al. 2005; Li 2011; Lam et al. 2015a, b).

In the context of seismic disaster, recent studies that focus on resilience or vulnerability assessment are generally based on loss estimation, particularly economic losses estimated from physical damage to infrastructures (Cho et al. 2001). Bruneau et al. (2003) developed a framework to assess community resilience to seismic disaster from economic losses and the speed of recovery using four resilience dimensions (technical, organizational, social, and economic) of five systems (global, electric power, water, hospital, and response and recovery systems). Chang and Shinozuka (2004) outlined a more succinct series of measures based on the framework developed by Bruneau et al. (2003) and reframed it in a probabilistic context. However, measurement of socioeconomic status is insufficient in the resilience assessment framework, which is usually based on loss estimation. As influence on life quality caused by seismic disasters draws increasing attention from the public, a need arises to consider the recovery and adaptive aspect of a community after disaster. For this reason, and by building on the RIM model, we assess community resilience to seismic disasters by choosing population growth rate as the key indicator of the recovery capability (Chang 2010; Finch et al. 2010; Li et al. 2010; Lam et al. 2015a) of counties in the area that were hit hard in Sichuan,
Gansu, and Shaanxi Provinces by the 2008 Wenchuan Earthquake.

The heavy mortalities and property losses caused by the 2008 Wenchuan Earthquake have captured extensive public attention, although few studies have been conducted concerning community resilience after the earthquake. Most studies were devoted to the physical aspect of the earthquake, such as studies on debris flow (Tang et al. 2012), landslide (Dai et al. 2011; Gorum et al. 2011; Tang et al. 2011; Xu et al. 2012; Guo and Hamada 2013), gas emission (Zheng et al. 2013), gravelly soil liquefication (Cao et al. 2011), surface deformation (Fu et al. 2011), and stress evolution (Nalbant and McCloskey 2011; Shan et al. 2013) of the Longmenshan fault zone (Li et al. 2013; Ran et al. 2013) triggered by the earthquake. Therefore, evaluating and quantifying community resilience in the earthquake-affected region to seismic disaster is needed.

\section{The Resilience Inference Measurement (RIM) Model}

This study adopts the definition used in NRC (2012) and considers resilience a broader concept that includes both vulnerability and adaptability over time. These two community attributes can lead to an outcome, which can be reflected in the condition of a community before, during, and after a disaster. In the RIM model, resilience is evaluated by two (dis)abilities_-vulnerability and adaptability. Vulnerability refers to a community's disability to minimize damage at the time of a disaster (Folk et al. 2002; Norris et al. 2008; Lam et al. 2015a), while adaptability is a community's ability to bounce back over time after a disaster (Brooks et al. 2005; Norris et al. 2008; Lam et al. 2015a). These two attributes can be measured from the three dimensions, including exposure (the intensity or number of times a community is hit by earthquake), damage (property damage), and recovery (population return) (Li 2011; Lam et al. 2015a). Vulnerability and adaptability indicate the relationships from exposure to damage and from damage to recovery, respectively (Fig. 1). Communities with high vulnerability are those suffering from high damage under low exposure. Similarly, communities with high adaptability recover quickly from

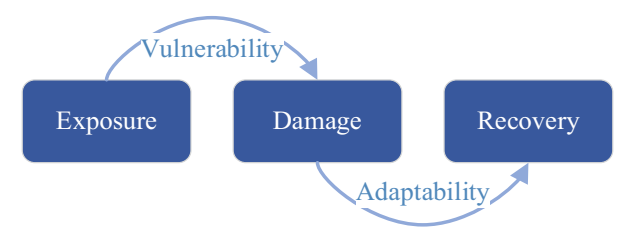

Fig. 1 The conceptual framework of the resilience inference measurement (RIM) model. Source Li (2011), Lam et al. (2015a) 

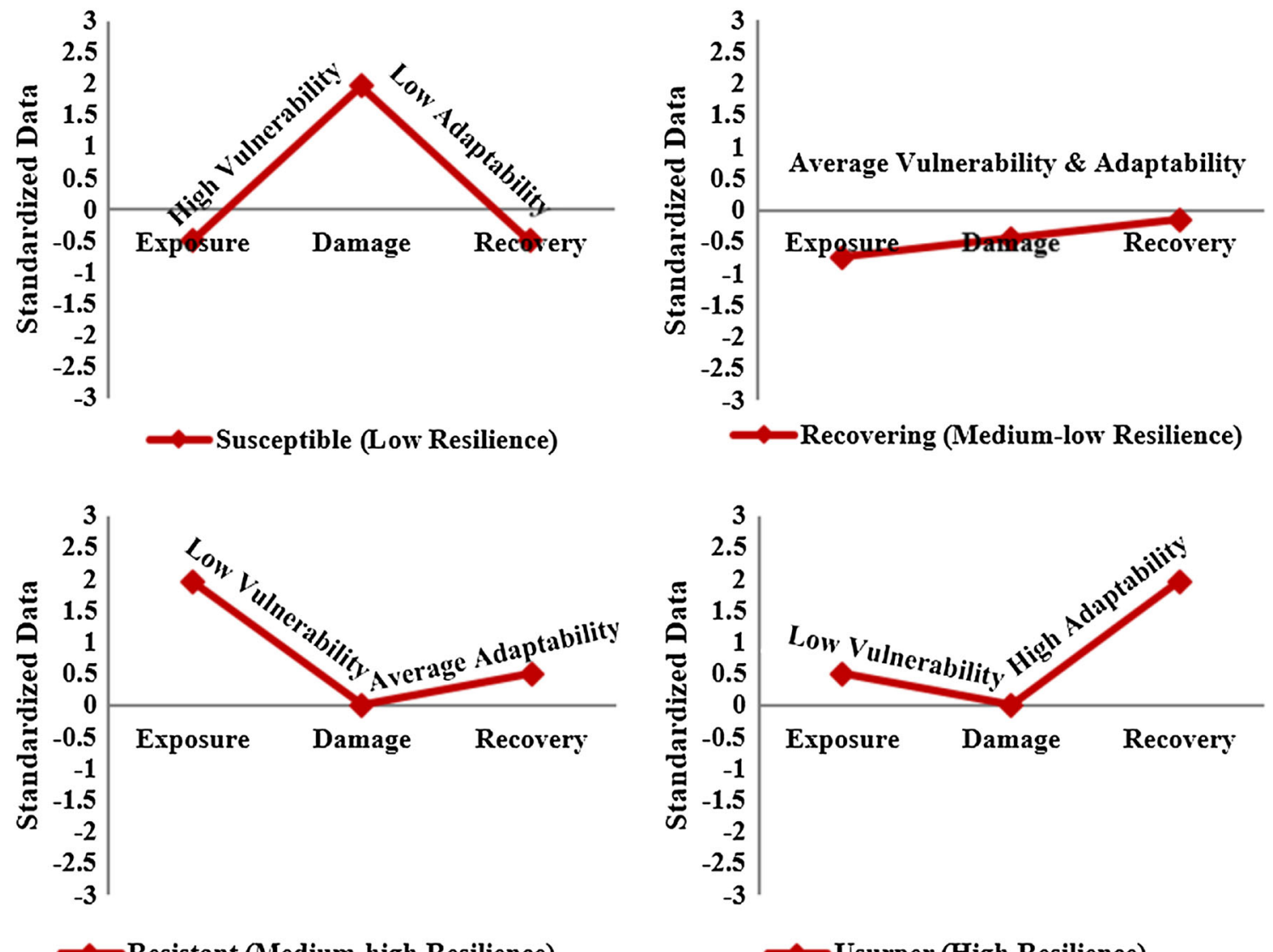

Resistant (Medium-high Resilience)

Fig. 2 Four states of resilience in the RIM framework. The y-axis shows the deviations of exposure, damage, and recovery from their means. Source Li (2011), Lam et al. (2015a)

high damage. They are represented as the slopes of the lines between exposure and damage and between damage and recovery in Fig. 2. There are four resilience rankings in the RIM framework. From high to low, the four states are: usurper, resistant, recovering, and susceptible (Lam et al. 2015a). Resilience of a community is classified as one of the resilience rankings according to vulnerability and adaptability. In general, susceptible communities have high vulnerability and low adaptability. Recovering and resistant communities both have average adaptability, and the difference is that recovering communities have average vulnerability while resistant have low vulnerability. Usurper communities, which are the opposite to susceptible communities, have low vulnerability and high adaptability (Li 2011; Lam et al. 2015a).

Applying the RIM model involves two statistical procedures. First, $K$-means cluster analysis was conducted to derive the a priori resilient rankings for the 105 counties (susceptible, recovering, resistant, and usurper). Each observation is regarded as a multidimensional real vector, and $K$-means cluster analysis segregates the $n$ observations into $k$ sets in order to minimize the within-cluster sum of squares (Hartigan and Wong 1979):

$$
\underset{S}{\arg \min } \sum_{i=1}^{k} \sum_{x_{j} \in S_{i}}\left\|x_{j}-\mu_{i}\right\|^{2}
$$

where $X=\left(x_{1}, \ldots, x_{n}\right)$ is the data matrix of observations, $S=\left\{S_{1}, \ldots, S_{k}\right\}$ stands for k sets, and $\mu_{i}$ is the mean of points in $S_{i}$.

Then, a number of socioeconomic indicators were used to validate the a priori resilient groups by discriminant analysis. Discriminant analysis is commonly used in constructing a function to distinguish a set of observations according to previously defined groups (Klecka 1980). Also it can be used to evaluate whether cases are classified as predicted. Given the independent variables (socioeconomic indicators) and dependent variable ( $K$-means groups) for each observation, discriminant analysis derives discriminant functions as a linear combination of independent variables (Klecka 1980):

$L=b_{1} x_{1}+b_{2} x_{2}+\cdots+b_{n} x_{n}+c$ 
where $b=\left\{b_{1}, \ldots, b_{n}\right\}$ are the discriminant coefficients which maximize the distance between the means of dependent variables; $x=\left\{x_{1}, \ldots, x_{n}\right\}$ are the independent variables for each observation; and $\mathrm{c}$ is a constant.

Based on the derived discriminant functions, classification functions can be computed. The procedure will then reclassify the observations into one of the four groups based on the observation's independent variables (for example, socioeconomic indicators). This posterior classification from discriminant analysis can be compared with the a priori classification from $K$-means analysis, and the classification accuracy can be used to indicate how good the set of independent variables are in distinguishing the four groups. If the classification accuracy is high and the statistical assumptions of discriminant analysis are met, the set of classification functions can be used to predict the resilience group membership for observations in other regions. Thus the RIM model for resilience assessment has two main advantages: validation by using the damage data and inferential potential by employing inferential statistics (Lam et al. 2015a).

The following further explains what we meant by validation. In the RIM model, the a prior groups are derived by $K$-means using real exposure and damage data. Then discriminant analysis is employed to validate the a prior grouping result by the 15 socioeconomic variables. The validation here means that the accuracy of the resilience groups derived by the discriminant analysis using the variables is compared with the groups derived from the cluster analysis. High classification accuracy means that the groups derived by the $K$-means are valid and the socioeconomic indicators can be used to characterize these resilient groups. Therefore, in this sense the RIM model has both an "external" validation where real observable outcomes were used to derive the resilience index and an "internal" validation where statistical accuracy and significance level are computed.

The pros of the RIM approach are that we derive the resilience metrics using the actual damage data. In addition, since discriminant analysis is an inferential statistical technique, the resultant classification functions can be used to predict resiliency in other regions, provided the statistical assumptions are met (Lam et al. 2015a). This approach is similar to some studies in the literature that use actual damage data as the dependent variable to regress with a set of indicators to determine variable selection and weighting (Peduzzi et al. 2009; Lam et al. 2014). As in any statistical/quantitative analysis including factor analysis and regression (Cutter et al. 2003; Li et al. 2016), the cons of the RIM approach are that all the variables used in the RIM framework are subject to different interpretations and definitions, time periods, and spatial scales. Moreover, the results may be relative only to the cases included in the study. However, by applying the model in different contexts (type of hazards), scales (spatial and temporal), and regions (different countries), we should be able to derive some generalizable indicators that may help in increasing resilience. The findings from this article can provide useful benchmark information on earthquake resilience in China.

\section{Measuring Resilience}

On 12 May 2008, a magnitude 7.9 devastating earthquake occurred in Wenchuan County $\left(31^{\circ} 00^{\prime} \mathrm{N}, 103^{\circ} 24^{\prime} \mathrm{E}\right)$, Sichuan Province. Six provinces and 15 million people were directly affected by the earthquake. An overwhelming majority of the mortalities and material damage occurred in the area around the epicenter, which lies in Sichuan, Gansu, and Shaanxi Provinces (Figs. 3, 4). In historical records, within a $200 \mathrm{~km}$ radius of the Wenchuan Earthquake epicenter, an earthquake equal to or above magnitude 7 takes place about every 40 years. The communities and cities in the surrounding region of Wenchuan County are highly exposed to earthquakes with high magnitude and huge destruction. Although this region is generally very vulnerable to earthquakes due to its weak economic base, less diverse industrial structure, and poor social resources, some counties performed better (for example, lost less and recovered more quickly) than others during and after the disasters (Guo 2012). Therefore, finding the factors that made some counties perform better than others is the key to promote resilience in a wider area.

\subsection{Study Area and Data}

Due to the data availability of reported damages and affected range of the earthquake, 105 counties around the epicenter of the Wenchuan Earthquake were selected as the study area, which lie across Sichuan, Shaanxi, and Gansu Provinces (Fig. 3). The study counties were selected according to the following criteria. First, the county was evaluated as being located within the worst-hit area by the China Earthquake Administration (CEA 2008). Second, economic loss data for the county were available from a credible source (in this case, the official yearbooks). Third, the county did not have more than a $10 \%$ change in its administrative boundaries between 2000 and 2011. Since socioeconomic data were collected during this period, significant boundary changes may bias the analysis. For example, about 15 counties in Sichuan Province, such as Songpan, Beichuan, Anxian, and others, had significant administrative boundary changes during 2002-2012. They 


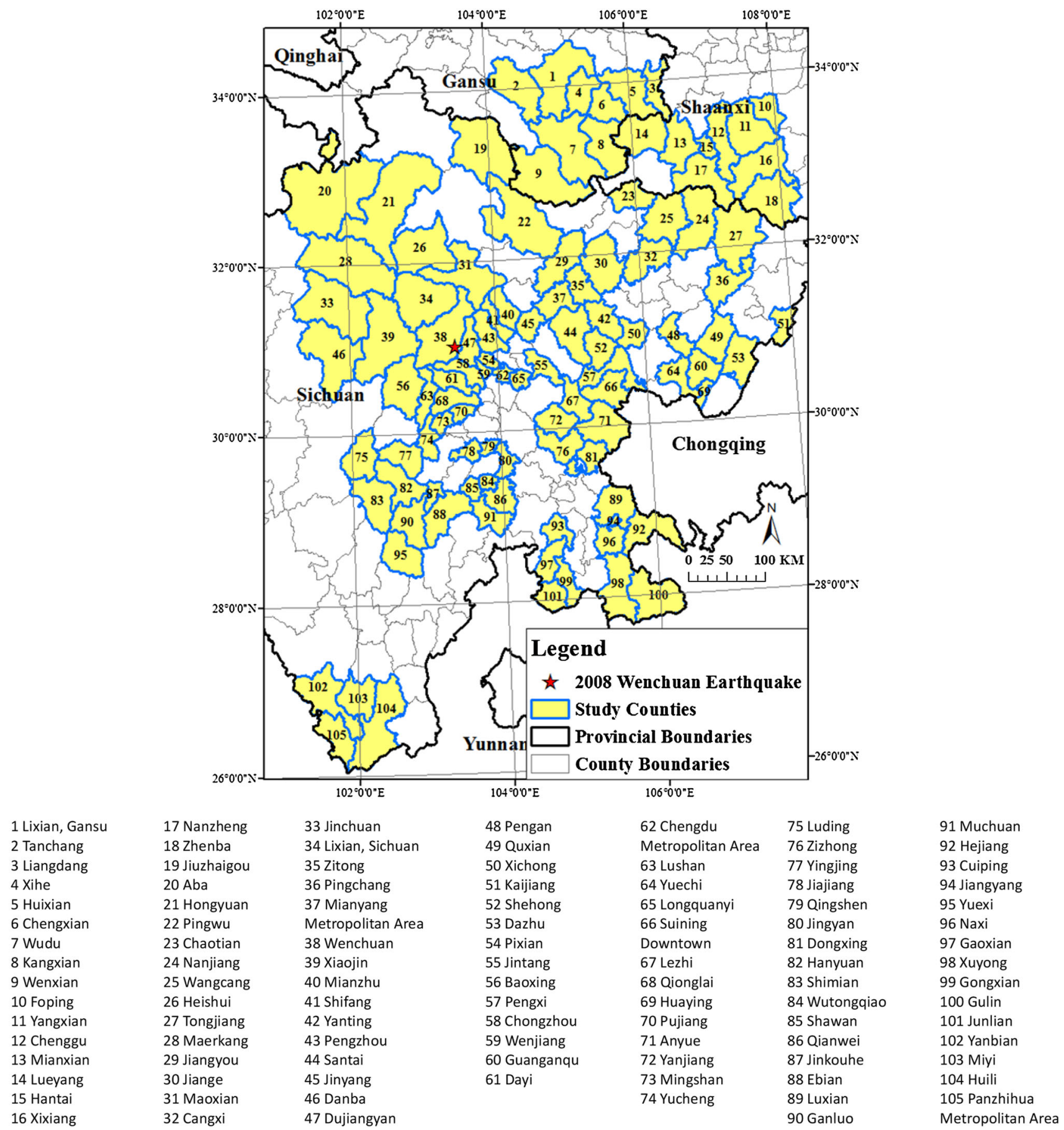

Fig. 3 Counties examined in this study

were not included in the study even though some of them experienced serious damage from the earthquake.

The RIM model has been used effectively in community resilience assessment for coastal hazards in the United States and in the Caribbean to extract major socioeconomic indicators ( $\mathrm{Li}$ et al. 2005, 2016; Li 2011; Lam et al. 2015a, b). Since earthquake disaster is similar to hurricanes in that it is large scale, high intensity, sudden onset, and destructive to all aspects of human activities, the RIM model can be adapted to evaluate the resilience of communities to earthquake by choosing appropriate indicators to represent the three critical dimensions (exposure, damage, and recovery). In this study: 


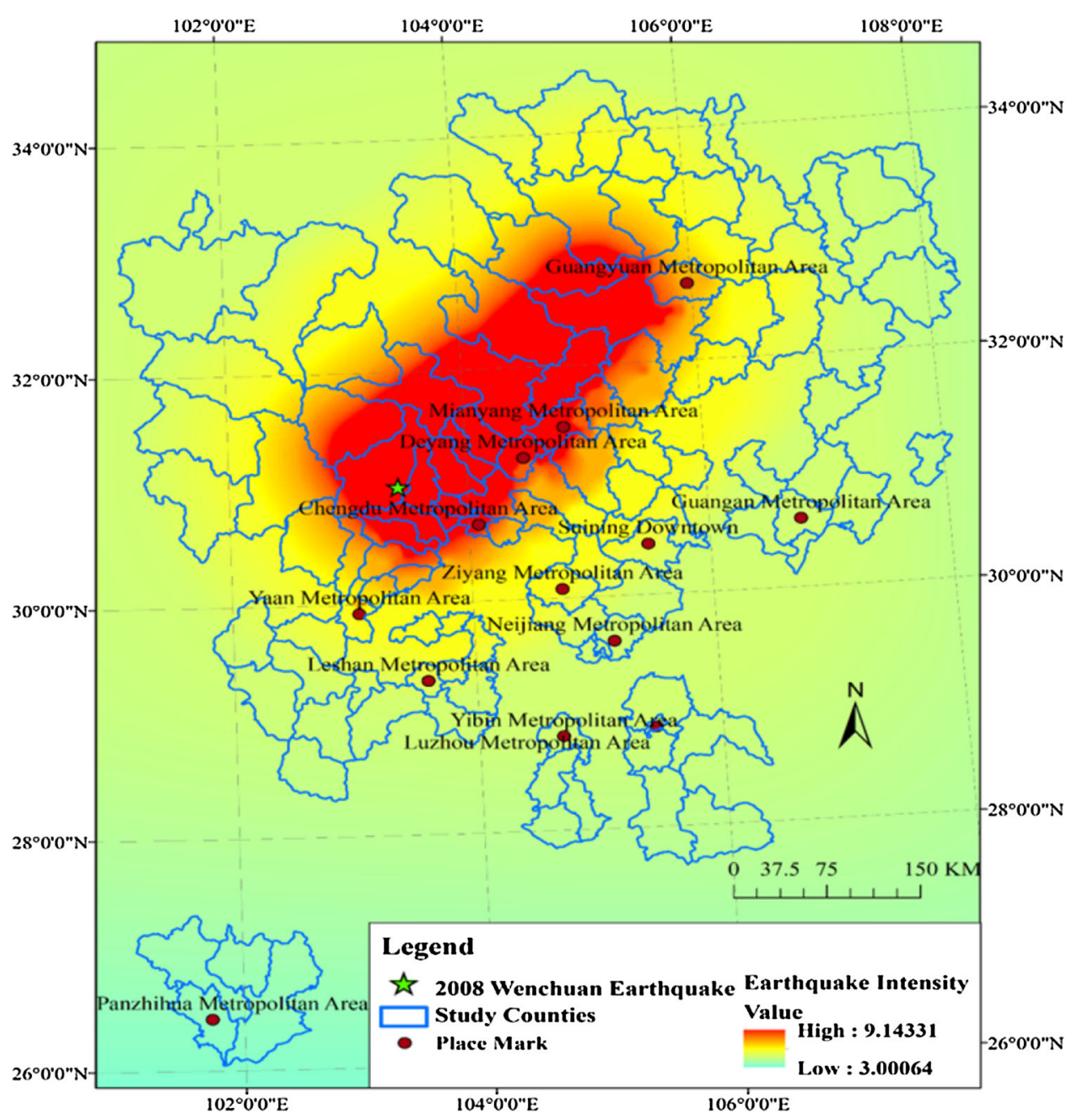

Fig. 4 Intensity distribution of the 2008 Wenchuan Earthquake

(1) The exposure indicator is the intensity of the 2008 Wenchuan Earthquake (Fig. 4), which is commonly used to quantify the destructiveness of seismic disaster (Eiby 1966). The intensity distribution of the earthquake was obtained from the U.S. Geological Survey (USGS 2008).

(2) Since there is very limited official publication of mortality data for the Wenchuan Earthquake at the county level, direct economic losses per capita caused by the earthquake was selected as the damage indicator. These data were collected from the 2009 yearbooks for Sichuan, Shaanxi, and Gansu published by their respective provincial governments (Sichuan Provincial Bureau of Statistics 2009; Shaanxi Provincial Bureau of Statistics 2009; Gansu Provincial Bureau of Statistics 2009). Economic losses are used as a variable of damage in many databases. Arguably the two most prominent and accessible are the Centre for Research on the Epidemiology of Disasters/Office of U.S. Foreign Disaster Assistance (CRED/OFDA) International Disaster Database (EM-DAT) housed in Belgium (Guha-Sapir et al. 2015) and the U.S. National Oceanographic and Atmospheric Administration National Climate Data Center (NOAA-NCDC) database (NOAA 2015). Economic loss is often the key variable used in disaster studies (Peduzzi et al. 2009; Lam et al. 2014).

(3) Recovery status is estimated by population growth rates from 2002 to 2011, which were obtained from the provincial statistical yearbooks published by the provincial bureaus of statistics (Sichuan Provincial Bureau of Statistics 2003, 2012; Shaanxi Provincial Bureau of Statistics 2003, 2012; Gansu Provincial Bureau of Statistics 2003, 2012). Researchers examining sources of recovery following disturbances have not reached consensus on the best way to measure recovery (Bevington et al. 2011). Although the recovery status of a county could be represented by 
other aspects, such as GDP and income growth, we chose population growth as the recovery indicator because the variable has often been seen to indicate the longer-term summative outcome of various aspects of recovery (Chang 2010; Li et al. 2010), and it is more stable and is probably the most accurate and accessible data in this region.

The intensity of the 2008 Wenchuan Earthquake ranged from 9.14 to 3.0 MMI (modified mercalli intensity scale) in the study area. The original data were in MMI contourpolygon form in intervals of 0.2 intensity units. The MMI original data were first interpolated into a raster of $6.72 \mathrm{~km}$ pixels (Fig. 4) by the Topo to Raster tool in ArcGIS 10. Then we utilized the Zonal tool to obtain the average intensity in each county to represent its exposure. The top five counties that had the highest exposure were all in Sichuan Province, including Mianzhu City (average intensity: 8.46 MMI), Shifang City (8.21 MMI), Dujiangyan City (8.15 MMI), Pengzhou City (8.07 MMI), and Wenchuan County (7.49 MMI).

As for the damage indicator, the top five counties that had the greatest economic loss per capita caused by the earthquake were Wenchuan County (618,269 Yuan), Lixian County (538,695 Yuan), Mianzhu City (276,848 Yuan), Shifang City (205,311 Yuan), and Maoxian County (203,669 Yuan), all in Sichuan Province (Fig. 3).

We chose population growth rate from 2002 (preseismic event status) to 2011 (post-event status) as the recovery indicator for each county. These years are close to the years of national population census, which is conducted every 10 years. By aligning the time period of the data with the national census, we can use the other socioeconomic variables from the census, which is critical to this study. There were no major changes in government policies during that time that could cause changes in the population growth rate. It is assumed that the population growth rate would otherwise remain stable if there was no earthquake damage in 2008.

The top five counties with the highest population growth rates were all from Sichuan Province as well, including Yuexi County (31.2\%), Chengdu Metropolitan Area (30\%), Hongyuan County (25\%), Aba County (22.95\%), and Wenjiang District (22.33\%). The bottom five counties that had the lowest population growth were Xixiang County $(-14.16 \%)$, Wenxian County $(-14.06 \%)$, Yangxian County $(-12.81 \%)$, Nanzheng County $(-12.39 \%)$, and Lixian County $(-11.8 \%)$. The population growth rate in Wenchuan County $(-9.82 \%)$ was lower than most of the counties in the study area, which reflected the difficulty Wenchuan County experienced in stimulating recovery after the earthquake.

\subsection{Clustering Resilience Groups}

Data of the three dimensions-exposure, damage, and recovery-were input to $K$-means cluster analysis to derive the four resilience groups. All the raw data had been converted into $z$-scores before the cluster analysis. Figure 5 plots the groups derived from the $K$-means analysis and Table 1 shows the number of counties in each cluster by $K$ means analysis. Figure 6 maps the group membership of the 105 counties.

The most severe economic losses occurred in Wenchuan County and Lixian County, which made up the susceptible group. The line graphs (Fig. 5) show that the average economic loss per capita in these two counties was much higher than the other resilience groups, although they did not experience the highest average intensity of the earthquake. A possible explanation is that the area badly suffered in Wenchuan County and Lixian County had high density of population, buildings, and infrastructure among the counties. Also, these two counties showed the lowest population growth after the earthquake. Both counties are located at the epicenter, and are thus expected to have the lowest resilience (Fig. 6). Our results show that resilience rose to the highest level in the counties immediately surrounding these two counties. The remaining counties farther away from the epicenter showed normal resilience.

\subsection{Discriminant Analysis}

After completing the cluster analysis, discriminant analysis was carried out to test whether the resilience level of a county can be predicted by its socioeconomic characteristics. Discriminant analysis was also used to validate the accuracy of the a priori groups.

In light of previous vulnerability and resilience research and considering the difference in data definition and availability in China (Cutter et al. 2003; Nelson et al. 2009), 15 socioeconomic variables that describe the

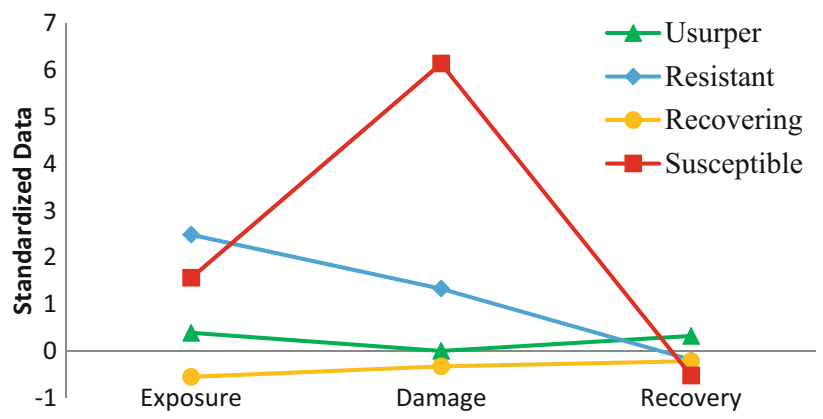

Fig. 5 Mean values of the four $K$-means clusters on the three resilience dimensions 
Table 1 Number of cases in each cluster from $K$-means and discriminant analysis

\begin{tabular}{lcl}
\hline Cluster & $K$-means & Discriminant analysis \\
\hline Usurper & 26 & 20 \\
Resistant & 7 & 10 \\
Recovering & 70 & 72 \\
Susceptible & 2 & 3 \\
\hline
\end{tabular}

preseismic event conditions of the counties were selected for the discriminant analysis (Table 2). The pre-event condition (Year 2000) should be used, instead of the post- event condition, to indicate how the underlying socioeconomic capacity can withstand disasters. These variables represented the demographic, social, economic, health, and social welfare capitals of each county in the study area. The values of the majority of the variables were collected from the 2000 population census published by the National Bureau of Statistics of the People's Republic of China (2001). The national population census is conducted every 10 years and Year 2000 is the closest year before the Wenchuan Earthquake. The other variables were collected from provincial yearbooks near 2000 to be consistent with the census variables, including the provincial statistical yearbooks published by the provincial bureaus of statistics

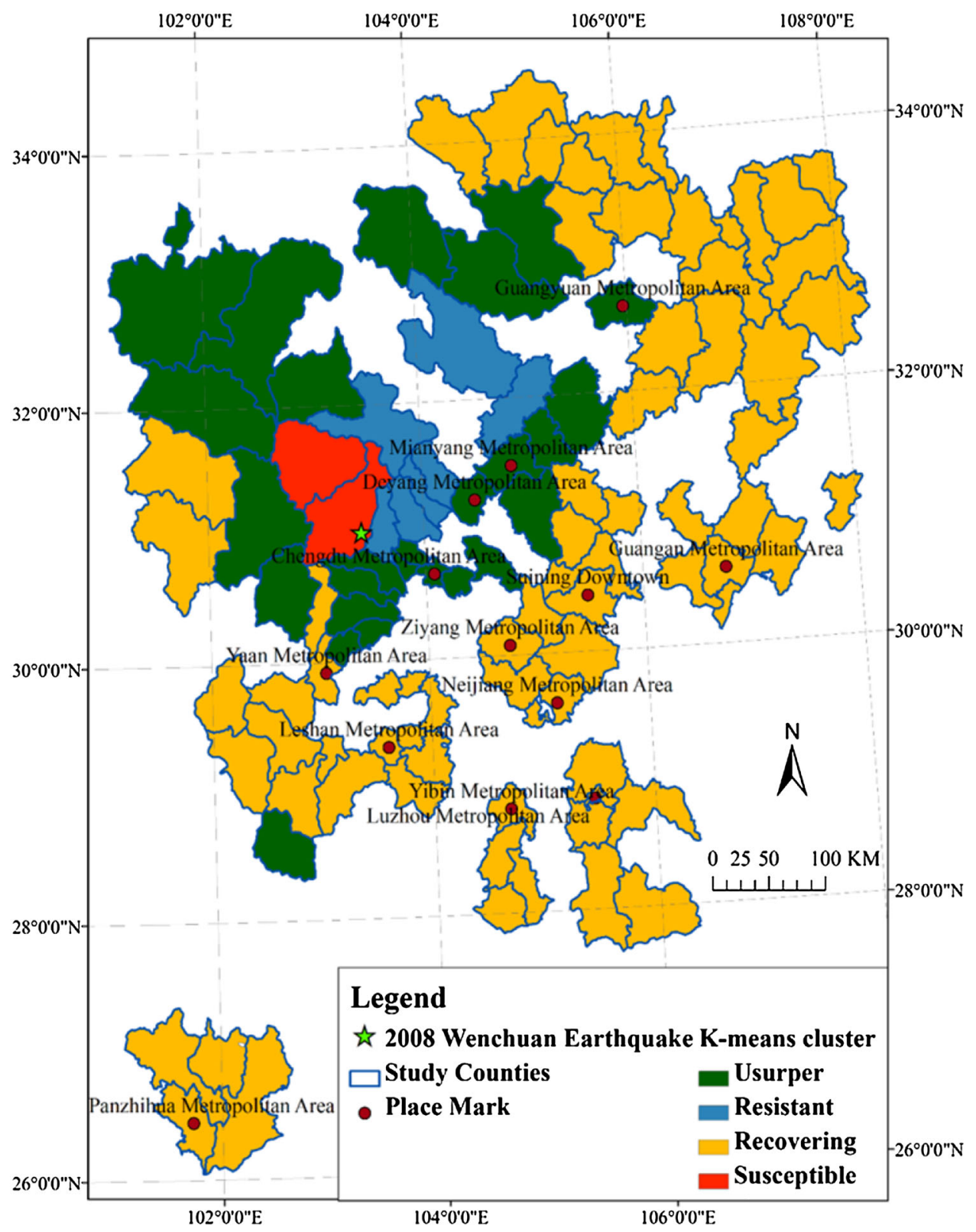

Fig. 6 Resilience groups derived by $K$-means cluster analysis 
Table 2 Socioeconomic variables for discriminant analysis. Source The 2000 population census data were obtained from the National Bureau of Statistics of the People's Republic of China (2001) (CS), and the 2002 socioeconomic data were from the provincial Statistical Yearbooks 2003 (YB)

\begin{tabular}{|c|c|c|c|c|}
\hline Label & Socioeconomic variable & Variable meaning & Unit & Source \\
\hline \multicolumn{5}{|l|}{ Demographic } \\
\hline PopDensity & Population density, 2002 & Population & Person $/ \mathrm{km}^{2}$ & YB \\
\hline SexRatio & Sex ratio, $2002($ female $=100)$ & Gender & $\%$ & YB \\
\hline RtoEthMinPop & Percentage of ethnic minorities population, 2000 & Ethnicity & $\%$ & CS \\
\hline RtoUrbanPop & Percentage of urban population, 2000 & Urban & $\%$ & $\mathrm{CS}$ \\
\hline RtoPopAge15-64 & Percentage of population age $15-64,2000$ & Age & $\%$ & $\mathrm{CS}$ \\
\hline \multicolumn{5}{|l|}{ Social } \\
\hline RtoEduSecSch & $\begin{array}{l}\text { Percentage of population with education of senior } \\
\text { secondary school and technical secondary school } \\
\text { and above, } 2000\end{array}$ & Education & $\%$ & CS \\
\hline RtoEmpPop & Employment ratio, 2000 & Employment & $\%$ & $\mathrm{CS}$ \\
\hline \multicolumn{5}{|l|}{ Economic } \\
\hline GDPperCapita & GDP per capita, 2002 (at current prices) & $\begin{array}{l}\text { Commercial \& industrial } \\
\text { development }\end{array}$ & Yuan/person & YB \\
\hline PPriIndus & Proportion of primary industry in GDP, 2002 & $\begin{array}{l}\text { Commercial \& industrial } \\
\text { development }\end{array}$ & $\%$ & YB \\
\hline PSecIndus & Proportion of secondary industry in GDP, 2002 & $\begin{array}{l}\text { Commercial \& industrial } \\
\text { development }\end{array}$ & $\%$ & YB \\
\hline GOVFFAF & $\begin{array}{l}\text { Gross output value of farming, forestry, animal } \\
\text { husbandry, and fishery per square kilometer } \\
\text { (at current prices), } 2002\end{array}$ & Agricultural activity & 10,000 yuan $/ \mathrm{km}^{2}$ & YB \\
\hline PCLA & Proportion of cultivated land area (year-end), 2002 & Agricultural activity & $\%$ & YB \\
\hline PCSvgsDpstB & $\begin{array}{l}\text { Per capita savings deposit balances of residents, } \\
2002\end{array}$ & Residential property & Yuan/person & YB \\
\hline \multicolumn{5}{|l|}{ Health } \\
\hline NoHospBed & Number of hospital beds per 10,000 persons, 2002 & Medical capacity & Unit/10,000 person & YB \\
\hline NoSWBed & $\begin{array}{l}\text { Number of social welfare home beds per 10,000 } \\
\text { persons, } 2002 \text { (including homeless shelters, } \\
\text { nursing homes, and hospices) }\end{array}$ & Social welfare & Unit/10,000 person & YB \\
\hline
\end{tabular}

(Sichuan Provincial Bureau of Statistics 2003; Shaanxi Provincial Bureau of Statistics 2003; Gansu Provincial Bureau of Statistics 2003).

Based on the vulnerability and resilience literature that is derived primarily from the Western countries (Cutter et al. 2003, 2010; Lam et al. 2015a), we hypothesize that 12 of the 15 variables - population density, sex ratio (male to female), percentage of urban population, percentage of population aged 15-64, percentage of population with more education, employment ratio, GDP per capita, gross output value of farming, forestry, animal husbandry, and fishery per square kilometer, proportion of cultivated land, per capita savings deposit balance of residents, per capita hospital beds, and per capita social welfare homes-contribute positively to resilience (Table 2). The higher the values of these variables are, the higher the resilience. Percentage of ethnic minorities is hypothesized to contribute negatively to resilience. The remaining two variables-proportion of primary industry and proportion of secondary industry - are less apparent, but at the start of the research it was expected that they would have opposite effects on the resilience ranking. In terms of county resilience assessment, it is logical to expect that counties close to the epicenter will sustain more damage because of higher earthquake intensity; these counties will take a longer time to recover and thus they have lower resilience.

Before performing discriminant analysis, the 15 socioeconomic variables were normalized by converting them into densities per square mile, per capita, or percentage.

The four a priori groups derived by $K$-means cluster analysis and the 15 predictor variables were entered into discriminant analysis in SPSS statistical package as grouping variables and independent variables. Using discriminant analysis, three discriminant functions that linearly combined predictor variables were obtained. Two of the discriminant functions, which explained 70.1 and $24.8 \%$ (accumulatively $94.9 \%$ ) of the total variance 
Table 3 Variance explained by discriminant functions

\begin{tabular}{lllll}
\hline Function & Eigenvalue & $\begin{array}{l}\% \text { of } \\
\text { variance }\end{array}$ & $\begin{array}{l}\text { Cumulative } \\
\%\end{array}$ & $\begin{array}{l}\text { Canonical } \\
\text { correlation }\end{array}$ \\
\hline 1 & 1.379 & 70.1 & 70.1 & 0.761 \\
2 & 0.487 & 24.8 & 94.9 & 0.572 \\
3 & 0.100 & 5.1 & 100.0 & 0.302 \\
\hline
\end{tabular}

(Table 3), were statistically significant, while the third function described the remaining $5.1 \%$ of the variance.

The discriminant functions provide probabilities of group membership for each county. According to the probability of group membership, each county was classified into one of the four groups. The group membership predicted by discriminant analysis matched $85.7 \%$ of the a priori groups derived from $K$-mean analysis, which means that the 15 selected socioeconomic variables can discriminate $85.7 \%$ of the 105 counties' resilience level. Only 15 counties were misclassified. The counties' resilience rankings and misclassified counties are shown in Table 4.

The results of the discriminant analysis can be evaluated further by the potency index of each variable, the plots of discriminant scores and variable loadings, the classification functions, and calculation of the probabilities of group memberships (Li 2011; Lam et al. 2015a).

\subsection{Spatial Distribution of Resilience}

The group memberships determined by the discriminant functions are illustrated in Fig. 7, which shows that 20 of the 105 counties were classified as Group Usurper and 10 were in Group Resistant, followed by 72 in Group Recovering and the remaining 3 in Group Susceptible. The spatial distribution of county resilience shows a generally spatially contiguous pattern. Counties in the epicenter area (Wenchuan County, Lixian County, and Maoxian County) had the lowest resilience to earthquake among all the study counties. Maoxian County was not classified as susceptible by $K$-means analysis but was classified as susceptible by discriminant analysis based on its socioeconomic variables. Counties east of the epicenter area (such as Pengzhou City, Mianyang Metropolitan Area, Pingwu County, and Shifang City) maintained high population growth despite the earthquake disaster. Counties in Chengdu City and Aba Prefecture generally had higher resilience to earthquake disaster than any other counties, such as Chengdu Metropolitan Area, Longquanyi District, and Wenjiang District. All of the counties in Gansu and Shaanxi Provinces were classified as Group Recovering. In general, counties in Group Susceptible were concentrated in the epicenter area, whereas counties immediately neighboring the three susceptible counties had high resilience rankings belonging in either the Usurper or the Resistant groups. With a few exceptions, the rest of the counties farther away from the epicenter were classified as Group Recovering by both $K$-means and discriminant analysis.

Nine of the 15 misclassified counties were in Group Usurper, in which six were downgraded to Group Recovering (Wenxian County, Wudu District, Chaotian District, Jiange County, Mingshan County, and Santai County) and the remaining three were downgraded to Group Resistant (Dayi County, Mianyang Metropolitan Area, and Qionglai City) by discriminant analysis.

\subsection{Potency Index}

The potency index of each variable can be used to evaluate the discriminant power of indicator variables using all significant discriminant functions (Perreault Jr et al. 1979). The potency index of variable $i$ is calculated as:

Potency $_{i}=\sum_{j=1}^{n} l_{i j}^{2} \times \frac{e_{j}}{\text { Sum of all } e_{j}}$,

where $n$ is the number of significant discriminant functions, $l_{i j}$. is the discriminant loading of variable $i$ on function $j$, and the eigenvalue of function $j$ is denoted as $e_{j}$.

The potency index of each variable can be used to evaluate its extent of influence on resilience. Table 5 ranks the 15 variables by their potency indices. It shows that sex ratio had the greatest influence on resilience, followed by per capita GDP, ethnicity, and medical facilities. Contrary to the initial hypothesis, a low sex ratio (meaning a high female proportion of the total population) was found to be associated with high-resilient counties. By comparing the average value of each variable in each resilience group, we found that counties in groups Usurper and Resistant had a: (1) higher proportion of population aged 15-64 (RtoPopAge15-64) and urban population (RtoUrbanPop); (2) higher GDP per capita and greater gross output value of agriculture per square kilometer (GOVFFAF); (3) higher ratio of population with an education of senior secondary school and above (RtoEduSecSch); and (4) larger savings deposit balance of residents per capita (PCSvgsDpstB). The recovering group had the highest proportion of primary industry and the lowest proportion of population with education of senior secondary school and above (RtoEduSecSch). The susceptible group also reveals some extreme characteristics on socioeconomic indicators, including a high proportion of male (SexRatio), a high proportion of ethnic minority population (RtoEthMinPop), a high proportion of secondary industry (PSecIndus), and a very low population density (PopDensity), gross output value of farming, forestry, animal husbandry, and fishery per square kilometer (GOVFFAF), and percent of cultivated land (PCLA). 
Table 4 County resilience rankings and misclassification

\begin{tabular}{|c|c|c|c|c|}
\hline Province & County & $K$-means & Discriminant & Misclassification \\
\hline \multirow[t]{9}{*}{ Gansu } & Chengxian & Recovering & Recovering & No \\
\hline & Huixian & Recovering & Recovering & No \\
\hline & Kangxian & Recovering & Recovering & No \\
\hline & Liangdang & Recovering & Recovering & No \\
\hline & Lixian (Gansu) & Recovering & Recovering & No \\
\hline & Tanchang & Recovering & Recovering & No \\
\hline & Wenxian & Usurper & Recovering & Yes \\
\hline & Wudu & Usurper & Recovering & Yes \\
\hline & Xihe & Recovering & Recovering & No \\
\hline \multirow[t]{9}{*}{ Shaanxi } & Chenggu & Recovering & Recovering & No \\
\hline & Foping & Recovering & Recovering & No \\
\hline & Hantai & Recovering & Recovering & No \\
\hline & Lueyang & Recovering & Recovering & No \\
\hline & Mianxian & Recovering & Recovering & No \\
\hline & Nanzheng & Recovering & Recovering & No \\
\hline & Xixiang & Recovering & Recovering & No \\
\hline & Yangxian & Recovering & Recovering & No \\
\hline & Zhenba & Recovering & Recovering & No \\
\hline \multirow[t]{40}{*}{ Sichuan } & Aba & Usurper & Usurper & No \\
\hline & Anyue & Recovering & Recovering & No \\
\hline & Baoxing & Usurper & Usurper & No \\
\hline & Cangxi & Recovering & Recovering & No \\
\hline & Chaotian & Usurper & Recovering & Yes \\
\hline & Chengdu $^{\mathrm{a}}$ & Usurper & Usurper & No \\
\hline & Chongzhou & Usurper & Usurper & No \\
\hline & Cuiping & Recovering & Recovering & No \\
\hline & Danba & Recovering & Recovering & No \\
\hline & Dayi & Usurper & Resistant & Yes \\
\hline & Dazhu & Recovering & Recovering & No \\
\hline & Dongxing & Recovering & Recovering & No \\
\hline & Dujiangyan & Resistant & Usurper & Yes \\
\hline & Ebian & Recovering & Recovering & No \\
\hline & Ganluo & Recovering & Recovering & No \\
\hline & Gaoxian & Recovering & Recovering & No \\
\hline & Gongxian & Recovering & Recovering & No \\
\hline & Guanganqu & Recovering & Recovering & No \\
\hline & Gulin & Recovering & Recovering & No \\
\hline & Hanyuan & Recovering & Recovering & No \\
\hline & Heishui & Usurper & Usurper & No \\
\hline & Hejiang & Recovering & Recovering & No \\
\hline & Hongyuan & Usurper & Usurper & No \\
\hline & Huaying & Recovering & Recovering & No \\
\hline & Huili & Recovering & Recovering & No \\
\hline & Jiajiang & Recovering & Recovering & No \\
\hline & Jiange & Usurper & Recovering & Yes \\
\hline & Jiangyang & Recovering & Recovering & No \\
\hline & Jiangyou & Resistant & Resistant & No \\
\hline & Jinchuan & Recovering & Usurper & Yes \\
\hline & Jingyan & Recovering & Recovering & No \\
\hline & Jinkouhe & Recovering & Recovering & No \\
\hline & Jintang & Usurper & Usurper & No \\
\hline & Jinyang & Usurper & Usurper & No \\
\hline & Jiuzhaigou & Usurper & Usurper & No \\
\hline & Junlian & Recovering & Recovering & No \\
\hline & Kaijiang & Recovering & Recovering & No \\
\hline & Lezhi & Recovering & Recovering & No \\
\hline & Lixian & Susceptible & Susceptible & No \\
\hline & Longquanyi & Usurper & Usurper & No \\
\hline
\end{tabular}


Table 4 continued

\begin{tabular}{|c|c|c|c|c|}
\hline Province & County & $K$-means & Discriminant & Misclassification \\
\hline & Luding & Recovering & Recovering & No \\
\hline & Lushan & Recovering & Recovering & No \\
\hline & Luxian & Recovering & Recovering & No \\
\hline & Maerkang & Usurper & Usurper & No \\
\hline & Maoxian & Resistant & Susceptible & Yes \\
\hline & Mianyang $^{\mathrm{a}}$ & Usurper & Resistant & Yes \\
\hline & Mianzhu & Resistant & Resistant & No \\
\hline & Mingshan & Usurper & Recovering & Yes \\
\hline & Miyi & Recovering & Recovering & No \\
\hline & Muchuan & Recovering & Recovering & No \\
\hline & Nanjiang & Recovering & Recovering & No \\
\hline & Naxi & Recovering & Recovering & No \\
\hline & Panzhihua $^{\mathrm{a}}$ & Recovering & Resistant & Yes \\
\hline & Pengan & Recovering & Recovering & No \\
\hline & Pengxi & Recovering & Recovering & No \\
\hline & Pengzhou & Resistant & Resistant & No \\
\hline & Pingchang & Recovering & Recovering & No \\
\hline & Pingwu & Resistant & Resistant & No \\
\hline & Pixian & Usurper & Usurper & No \\
\hline & Pujiang & Usurper & Usurper & No \\
\hline & Qianwei & Recovering & Recovering & No \\
\hline & Qingshen & Recovering & Recovering & No \\
\hline & Qionglai & Usurper & Resistant & Yes \\
\hline & Quxian & Recovering & Recovering & No \\
\hline & Santai & Usurper & Recovering & Yes \\
\hline & Shawan & Recovering & Recovering & No \\
\hline & Shehong & Recovering & Recovering & No \\
\hline & Shifang & Resistant & Resistant & No \\
\hline & Shimian & Recovering & Recovering & No \\
\hline & Suining $^{\mathrm{a}}$ & Recovering & Recovering & No \\
\hline & Tongjiang & Recovering & Recovering & No \\
\hline & Wangcang & Recovering & Recovering & No \\
\hline & Wenchuan & Susceptible & Susceptible & No \\
\hline & Wenjiang & Usurper & Usurper & No \\
\hline & Wutongqiao & Recovering & Recovering & No \\
\hline & Xiaojin & Usurper & Usurper & No \\
\hline & Xichong & Recovering & Recovering & No \\
\hline & Xuyong & Recovering & Recovering & No \\
\hline & Yanbian & Recovering & Resistant & Yes \\
\hline & Yanjiang & Recovering & Recovering & No \\
\hline & Yanting & Recovering & Usurper & Yes \\
\hline & Yingjing & Recovering & Recovering & No \\
\hline & Yucheng & Recovering & Recovering & No \\
\hline & Yuechi & Recovering & Recovering & No \\
\hline & Yuexi & Usurper & Usurper & No \\
\hline & Zitong & Usurper & Usurper & No \\
\hline & Zizhong & Recovering & Recovering & No \\
\hline
\end{tabular}

"Metropolitan area: "No" in the misclassification column stands for accurate classification based on cluster analysis result. "Yes" in the misclassification column stands for misclassification based on cluster analysis result

\subsection{Discriminant Score and Variable Loading}

The discriminant scores of the counties in the four resilience groups were plotted onto the first two functions in Fig. 8. The plot clearly shows that the Usurper, Recovering, and Susceptible groups were well separated using the two functions, while Group Resistant mainly overlapped with Group Usurper. In terms of spatial distribution (Fig. 7), counties in Group Usurper and Resistant were often in adjacent areas. The socioeconomic characteristics of the counties were similar in both groups (Fig. 8). That also was the reason that about $40 \%$ (6 out of 15) of 


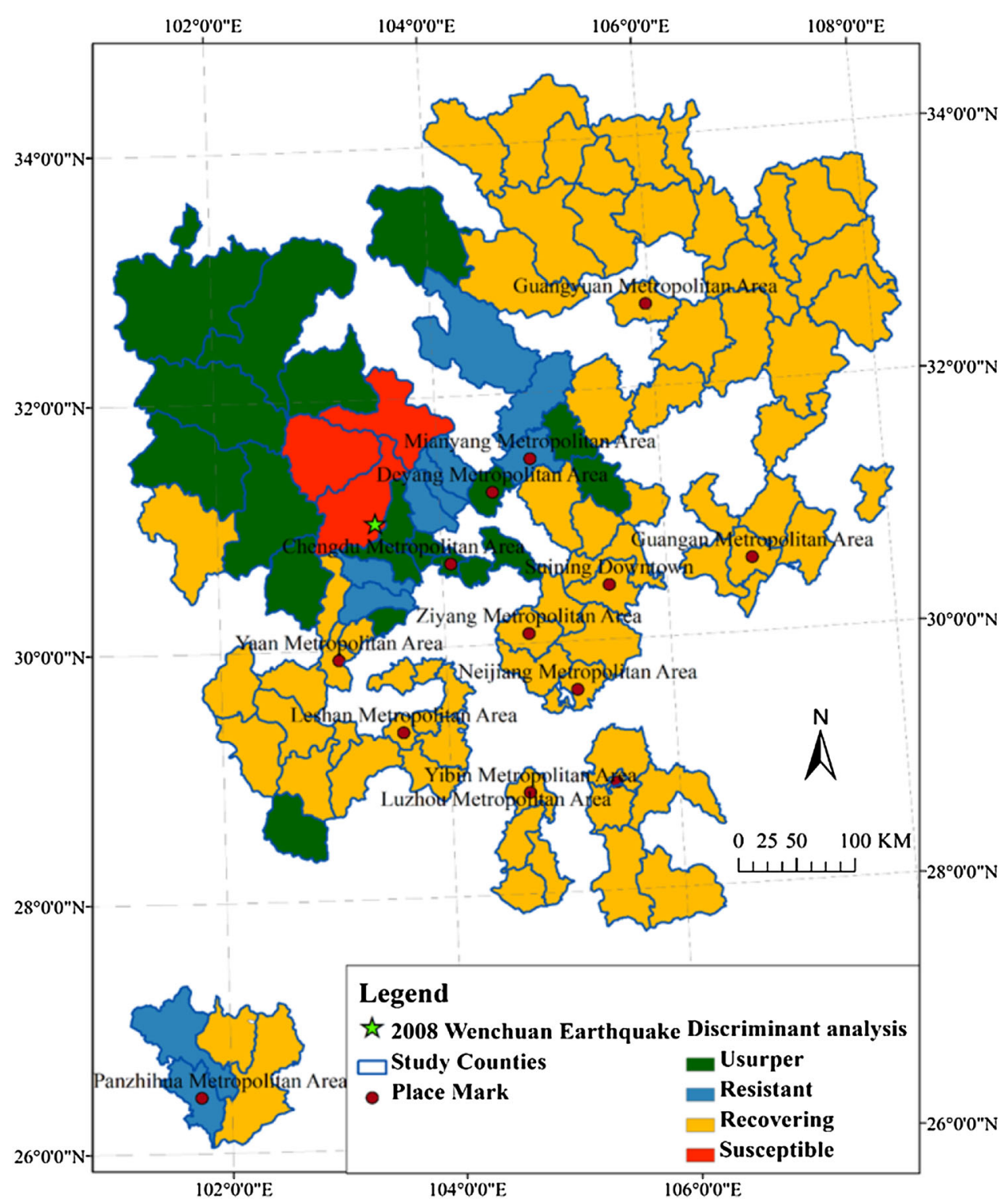

Fig. 7 Resilience rankings derived by discriminant analysis

misclassification counties were downgraded from Group Usurper to Groups Resistant and Recovering.

In Fig. 9, the loadings of the indicator variables were plotted onto the first two discriminant functions to further explain the associations between the socioeconomic indicators and resilience groups. From the two plots of discriminant scores and variable loadings (Figs. 8, 9), as well as Table 5 (mean value of each variable in each group), we can make several observations.

First, the discriminant analysis results indicate that the resilience of the top two most resilient groups, Groups Usurper and Resistant (green and blue areas in Fig. 7) was characterized by high values of the following eight variables: GDP per capita; gross output value of farming, forestry, animal husbandry, and fishery per square kilometer; percentage of population aged 15-64; percentage of urban population; resident saving deposit balances per capita; per capita social welfare beds; percentage of population with education of senior secondary school and above; percent of cultivated land; and population density. Counties belonging to the Usurper and Resistant groups were mostly associated with economically developed and highly populated areas such as those in Chengdu City, Mianyang City, and Deyang City. We can interpret that GDP per capita and gross output value of farming, forestry, animal husbandry, and fishery per square kilometer are indicators of the economic state of a county. The state of prequake economic health might have helped in longerterm recovery after the earthquake. Counties with higher percentages of urban population and per capita saving 
Table 5 Potency index and mean value of each variable in each group derived from discriminant analysis

\begin{tabular}{|c|c|c|c|c|c|}
\hline \multirow[t]{2}{*}{ Variables } & \multicolumn{4}{|c|}{ Mean value } & \multirow[t]{2}{*}{ Potency index } \\
\hline & Usurper & Resistant & Recovering & Susceptible & \\
\hline SexRatio & 104.49 & 106.13 & 109.54 & 112.38 & 0.131 \\
\hline GDPperCapita & 8772.65 & 11173.22 & 3840.21 & 6991.78 & 0.129 \\
\hline RtoEthMinPop & 30.65 & 5.87 & 4.38 & 76.55 & 0.098 \\
\hline NoHospBed & 35.20 & 32.64 & 20.81 & 37.72 & 0.062 \\
\hline GOVFFAF & 116.35 & 94.67 & 59.76 & 3.05 & 0.055 \\
\hline RtoPopAge15-64 & 70.75 & 73.15 & 68.71 & 68.78 & 0.046 \\
\hline PSecIndus & 32.48 & 47.51 & 35.22 & 54.21 & 0.043 \\
\hline PPriIndus & 25.58 & 17.82 & 32.15 & 17.56 & 0.042 \\
\hline RtoUrbanPop & 31.76 & 38.47 & 19.92 & 18.09 & 0.033 \\
\hline PCSvgsDpstB & 5334.66 & 5656.38 & 2857.18 & 3238.90 & 0.030 \\
\hline RtoEduSecSch & 12.30 & 12.09 & 8.41 & 11.79 & 0.026 \\
\hline NoSWBed & 4.26 & 9.81 & 5.26 & 0.38 & 0.023 \\
\hline RtoEmpPop & 61.55 & 63.91 & 62.40 & 60.92 & 0.021 \\
\hline PCLA & 18.13 & 17.01 & 16.48 & 1.08 & 0.019 \\
\hline PopDensity & 660.60 & 371.46 & 342.19 & 21.46 & 0.019 \\
\hline
\end{tabular}

Variables are listed from highest to lowest according to the potency index

deposit balances might be more resilient, as more wealth can help the county reduce and recover from damage quicker. Higher percentages of population with education of senior secondary school and above and population aged 15-64 also characterize a resilient county because they are important in technology innovation and boosting economic vitality, which could promote the resilience of a county.

Second, Group Recovering (gold areas in Fig. 7) was characterized with high values of sex ratio and proportion of primary industry, but low values of per capita hospital beds and education. These underdeveloped counties were found to have lower resilience to earthquake disaster. A higher proportion of primary industry with a moderate level of gross output value of farming, forestry, animal husbandry, and fishery per square kilometer indicates a county is economically backward, which could need more time to recover from the earthquake. A lower proportion of educated population reflects a lack of technology innovation of a county, which could make the economy develop slowly and the counties more susceptible to hazard.

Third, Group Susceptible (red area in Fig. 7) includes three counties as classified by discriminant analysis. Wenchuan County and Lixian County, which are located in the epicenter area, were severely impacted by the Wenchuan Earthquake, and had more property damage than other counties. These counties were classified as susceptible by $K$-means analysis. Maoxian County was originally classified as resistant by $K$-means, but, based on its socioeconomic characteristics, Maoxian was classified as Susceptible. Figures 8 and 9 show that the Susceptible group is characterized by high values of sex ratio and percentage of ethnic minority population. The group also has the lowest values of five variables: gross output value of farming, forestry, animal husbandry, and fishery per square kilometer; urban population; percentage of social welfare beds; percentage of cultivated land; and population density. High percentage of ethnic minority population is mostly associated with societies of cultural diversity, poor economy, and less-developed education in China (Shan 2010). The local government usually adopts a more conservative disaster response policy because of a lack of technical support in the minority area (Shan 2010). Furthermore, poor social welfare services would indirectly decrease the resiliency of the counties, since the objectives of the social welfare service are to serve the disadvantaged groups of society, and they are generally more vulnerable and need additional support in the disaster recovery period.

\section{Discussion}

This study measured 105 communities' resilience in the region that was greatly affected by the 2008 Wenchuan Earthquake by using a quantitative measurement approach, the resilience inference measurement (RIM) model. Comparison of the RIM assessment results with the hypothetical relationships posted in Sect. 4.3 merits further discussion.

In terms of the county resilience assessment, it was hypothesized that counties close to the epicenter would sustain more damage because of higher earthquake intensity; these counties would presumably take a longer time to recover from earthquake impacts and thus they would have 


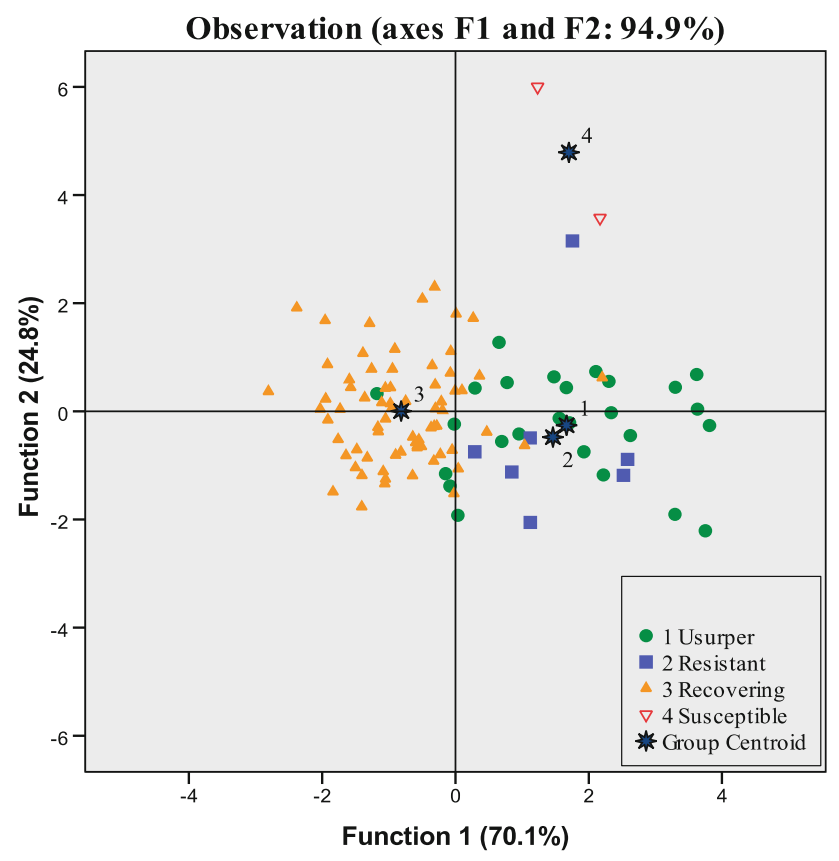

Fig. 8 Plot of the four resilience groups on the first two discriminant functions

a lower resilience. Our results indicate that the three counties (Wenchuan, Lixian, Maoxian) located in the epicenter region had the lowest resilience level. But the counties immediately surrounding these three counties had the highest level of resilience. In fact, it was the counties farther away from the epicenter that exhibited the lower resilience level. This finding is somewhat unexpected, as counties closer to the epicenter suffered from higher earthquake intensity (Fig. 4) and high damage, and thus were expected to recover more slowly. A possible reason for this spatial pattern is that the epicenter is located in a

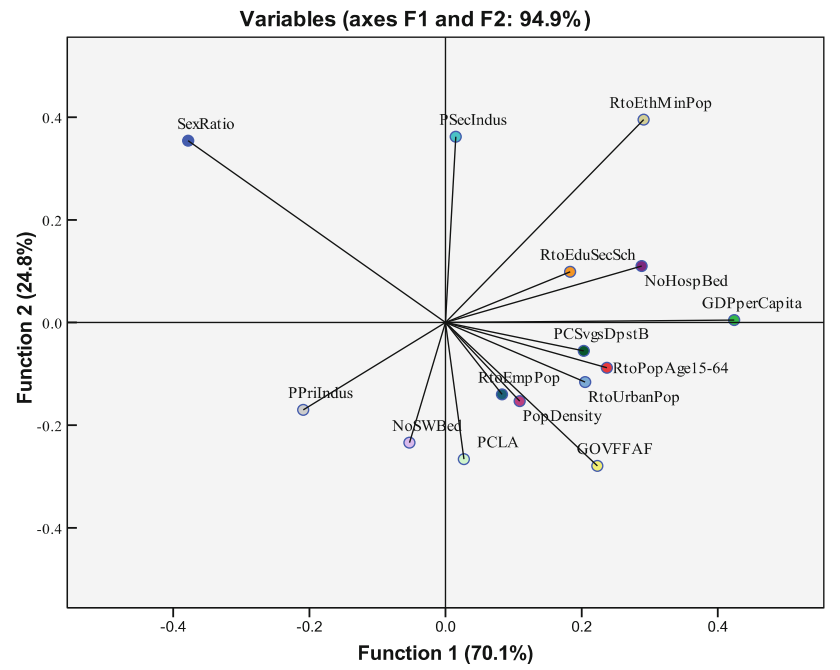

Fig. 9 Plot of the 15 variables on the first two discriminant functions region with high historical earthquake frequency (Sect. 4.1). Local residents may have been more aware of the hazards and hence were better prepared and adapted (Chang and Shinozuka 2004). It is also possible that people moving from the epicenter to nearby counties might partly affect the result. Unfortunately, migration data after the earthquake are not available, especially for a large region like the one examined in this study. This data problem is similar to the Hurricane Katrina event in Louisiana where migration data are difficult to obtain and verify at a larger spatial scale (Lam et al. 2009, 2012). Additional factors, such as financial incentives, access to markets, and political stipulations may also explain this spatial pattern, which deserves exploration in future research.

The 15 socioeconomic variables chosen to analyze the resilience of the earthquake-prone area that was exposed to seismic hazard were based not only on the RIM model but also on a broader disaster resilience literature. We realized that comparing the United States case to China would be challenging. The variables were selected based on their similar meanings to the United States variables and data availability. We also have to choose the statistical data at the county scale from the most credible source. In addition, the variables that may be deemed useful to developing countries, such as sex ratio, are included if they are available. These variables were used to validate the accuracy of resilience groups derived by cluster analysis. The validation, with an $85.7 \%$ accuracy, provides the following information: (1) the importance of the variables in general community resilience assessment; (2) the characteristics of community resilience in the study area; and (3) the possibility to predict resiliency by using the same variables in other parts of China in the future.

The relationships between individual variables and resilience rank may not be as clear and straightforward as postulated in the hypotheses. This ambivalence is due to the complex nature of resilience assessment for a large study area. But by comparing the mean values of each variable between the highest and the lowest resilience groups (usurper and susceptible) (Table 5), we can conclude that 10 of the 12 variables that we hypothesized to have a positive contribution to resilience can be confirmed. These 10 variables included: population density; percentage of urban population; percentage of population age 15-64; percentage of population with more education, employment ratio; GDP per capita; gross output value of farming, forestry, animal husbandry, and fishery per square kilometer; proportion of cultivated land; per capita savings deposit balance of residents; and per capita social welfare beds (including homeless shelters, nursing homes, and hospices). Two other variables, sex ratio (male to female) and per capita hospital beds, show a negative relationship with the resilience rank. The hypothesis that percentage of 
ethnic minorities contributes negatively to resilience is also confirmed. The hypothesis that the two remaining variables-proportion of primary industry and proportion of secondary industry-have opposite effects on the resilience rank is also true, with the former contributing positively to resilience and the latter negatively to resilience. Taking Wenchuan County and Lixian County as examples, their manufacturing-oriented economy and low proportion of primary industry are associated with dense buildings and infrastructure, which might suffer more serious damage and need longer time to recover from the earthquake.

The potency index has shown that sex ratio had the greatest influence on our resilience assessment, followed by per capita GDP, ethnicity, and medical facilities. A low sex ratio means a high proportion of females, and the assessment result shows that the lower the ratio, the higher the county's resilience. Although there is little published evidence in a Chinese context to support our interpretation, we suggest that the sex ratio can be treated as a broad indicator of community characteristics, and in China it may mean that counties with high resilience are the more developed, and the more economically developed counties have better work opportunities and equity education for females. This sex-ratio variable is different from the variable of percent of female-headed households often used in the United States, where the latter is often associated with poverty, low-income status, and low resilience (Lam et al. 2009, 2012).

The results may change with different definitions of variables as in most studies. (1) For the exposure indicator: we consider intensity as an appropriate indicator for the seismic disaster. It might be more reasonable to choose multiple exposure indicators for another disaster, like floor or hurricane. (2) For the damage indicator: limited by the official publication of statistical data for the Wenchuan Earthquake at the county level, direct economic losses per capita caused by the earthquake could be the only appropriate choice to indicate the overall damage situation. (3) For the recovery indicator: in this study, we set population growth as the recovery indicator. Population growth has been similarly used by many studies (Chang 2010; Finch et al. 2010; Li et al. 2010). To explore how sensitive the model validation process is, an experiment using the GDP growth ratio as the recovery variable was conducted, and the results were quite similar to those obtained from using the population growth ratio.

Limited by the data availability, we had to use only 15 variables from the census and other statistical sources to describe the social, economic, health, and social welfare characteristics of the Wenchuan Earthquake study area. In future studies, it would be useful to include additional variables to examine a more holistic representation of disaster resilience in the region, such as variables on ecological indicators, infrastructural characteristics, local government policies, and community connectedness. Taking the governmental policy on post-disaster recovery from the Wenchuan Earthquake as an example, several funds had been identified for post-disaster reconstruction after extreme disasters took place. The Chinese government invested RMB 654.5 billion Yuan in stricken communities to promote post-Wenchuan Earthquake recovery and reconstruction, especially in the epicenter area and surrounding counties (State Council of the People's Republic of China 2010). The post-disaster reconstruction investment not only aims to promote recover and reconstruction in the epicenter area and surrounding counties, but also regards restoration as an opportunity for regional socioeconomic redevelopment (Guo 2012). It is possible that these funds could partly promote the high resilience of counties surrounding the epicenter area. Moreover, differences in urban planning of reconstruction and redevelopment in different places can affect the effectiveness of the investment substantially. This is probably the reason why Dujiangyan, which experienced significant post-disaster governmental-led urban development, was originally classified as "resistant" by $K$-means analysis but became a "usurper" by discriminant analysis based on the set of socioeconomic variables.

\section{Conclusion}

In this study, we applied the RIM model to assess the resilience status of 105 counties in southwestern China after the 2008 Wenchuan Earthquake. We then interpreted community resilience based on the socioeconomic characteristics of each county. We also evaluated the discriminant power of every indicator, and demonstrated the association between indicators and resilience ranks across the impacted region. We found that counties located right at the epicenter area (Wenchun, Lixian, and Maoxian) had the lowest resilience, but counties immediately surrounding the epicenter area had the highest resilience. Counties that were farther away from the epicenter returned rapidly to their prequake low resilience (the Recovering Group). That counties surrounding the epicenter-counties (not those at the epicenter) had the highest resilience values was largely a result of preevent conditions, and the degree of usefulness of the preevent conditions to inform resiliency is reflected by the discriminant analysis's classification accuracy. Through discriminant analysis, we found that the 15 selected socioeconomic variables were able to predict resilience group membership with a reasonably high degree of accuracy $(85.7 \%)$. The top four variables that showed great influence on resilience were: sex ratio, per capita 
GDP, percent of ethnic minorities, and average number of hospital beds.

The contributions of this study can be summarized succinctly:

- This study produced the first quantitative analysis of community resilience assessment to seismic disaster in the study area. The findings should provide useful benchmark information on community resilience assessment to seismic events in China where socioeconomic conditions are very different from other countries.

- The assessment results provide insights and decisionmaking support for policy making regarding disaster resilience.

- This study shows that the RIM model could be utilized as a useful alternative approach to community resilience assessment.

- Although different countries have different cultural backgrounds, stage of economic progress, and national policies, some broad indicators of disaster resilience can still be extracted. At the same time, some unique characteristics may also be identified.

Our study contributes to the literature and our findings provide useful insights to strategies that could help increase resilience worldwide. In future research, we could extend the RIM model to study various disasters in different places, and establish a set of more comprehensive and multidimensional indices as exposure, damage, and recovery indicators to assess the characteristics of community resilience. It will be greatly helpful to look at multiple disaster events or disaster chain in the same area. It is possible to add ecosystem, policy, and other factors to our data and models. Also it will be useful to study the similarities and differences of community resilience in different areas and construct the human-nature coupled disaster-response system.

Acknowledgements This article is partially based on work supported by the US National Science Foundation (Award number 1212112) and the Louisiana Sea Grant program, the China Postdoctoral Science Foundation (No. 2016M592647), the National Natural Science Foundation of China (Grant No. 61305022), and the Opening Fund of State Key Laboratory of Virtual Reality Technology and Systems (Beihang University) (Grant No. BUAA-VR-16KF-11). Views, findings, conclusions, and recommendations expressed in this article are those of the authors and do not necessarily reflect the views of the funding agencies.

Open Access This article is distributed under the terms of the Creative Commons Attribution 4.0 International License (http://crea tivecommons.org/licenses/by/4.0/), which permits unrestricted use, distribution, and reproduction in any medium, provided you give appropriate credit to the original author(s) and the source, provide a link to the Creative Commons license, and indicate if changes were made.

\section{References}

Adger, W.N., K. Brown, and D. Conway. 2010. Progress in global environmental change. Global Environmental Change 20(4): 547-549.

Bevington, J.S., A.A. Hill, R.A. Davidson, S.E. Chang, A. Vicini, B.J. Adams, and R.T. Eguchi. 2011. Measuring, monitoring, and evaluating post-disaster recovery: A key element in understanding community resilience. In Proceedings of ASCE Structures Congress 2011, ed. D. Ames, T.L. Droessler, and M. Hoit, 2033-2043. Reston, VA: American Society of Civil Engineers.

Boruff, B.J., C. Emrich, and S.L. Cutter. 2005. Erosion hazard vulnerability of US coastal counties. Journal of Coastal Research 21(5): 932-942.

Brooks, N., W.N. Adger, and P.M. Kelly. 2005. The determinants of vulnerability and adaptive capacity at the national level and the implications for adaptation. Global Environmental Change 15(2): 151-163.

Bruneau, M., S.E. Chang, R.T. Eguchi, G.C. Lee, T.D. O'Rourke, A.M. Reinhorn, M. Shinozuka, K. Tierney, W.A. Wallace, and D. von Winterfeldt. 2003. A framework to quantitatively assess and enhance the seismic resilience of communities. Earthquake Spectra 19(4): 733-752.

Bruneau, M., and A.M. Reinhorn. Overview of the resilience concept. In Proceedings of the 8th U. S. National Conference on Earthquake Engineering, 18-22 April, 2006, San Francisco, California, USA.

Cao, Z., T.L. Youd, and X. Yuan. 2011. Gravelly soils that liquefied during 2008 Wenchuan, China Earthquake, Ms = 8.0. Soil Dynamics and Earthquake Engineering 31(8): 1132-1143.

CEA (China Earthquake Administration). 2008. Seismic intensity map of the Ms 8.0 Wenchuan Earthquake. http://www.cea.gov. $\mathrm{cn} / \mathrm{manage} / \mathrm{html} / 8 \mathrm{a} 8587881632 \mathrm{fa} 5 \mathrm{c} 0116674 \mathrm{a} 018300 \mathrm{cf} /$ content/ 08_09/01/1220238314350.html. Accessed 27 May 2015.

Chang, S.E. 2010. Urban disaster recovery: A measurement framework and its application to the 1995 Kobe earthquake. Disasters 34(2): 303-327.

Chang, S.E., and M. Shinozuka. 2004. Measuring improvements in the disaster resilience of communities. Earthquake Spectra 20(3): 739-755.

Chen, G., F. Ji, R. Zhou, J. Xu, B. Zhou, X. Li, and Y. Ye. 2007. Primary research of activity segmentation of Longmenshan fault zone since late-quaternary. Seismology and Geology 29(3): 657-673 (in Chinese).

Cho, S., P. Gordon, J.E.I. Moore, H.W. Richardson, M. Shinozuka, and S. Chang. 2001. Integrating transportation network and regional economic models to estimate the costs of a large urban earthquake. Journal of Regional Science 41(1): 39-65.

Cutter, S.L., K.D. Ash, and C.T. Emrich. 2014. The geographies of community disaster resilience. Global Environmental Change 29: $65-77$.

Cutter, S.L., L. Barnes, M. Berry, C. Burton, E. Evans, E. Tate, and J. Webb. 2008. A place-based model for understanding community resilience to natural disasters. Global Environmental Change 18(4): 598-606.

Cutter, S.L., B.J. Boruff, and W.L. Shirley. 2003. Social vulnerability to environmental hazards. Social Science Quarterly 84(2): 242-261.

Cutter, S.L., C.G. Burton, and C.T. Emrich. 2010. Disaster resilience indicators for benchmarking baseline conditions. Journal of Homeland Security and Emergency Management 7(1): $1271-1283$.

Dai, F.C., C. Xu, X. Yao, L. Xu, X.B. Tu, and Q.M. Gong. 2011. Spatial distribution of landslides triggered by the 2008 Ms 8.0 
Wenchuan earthquake, China. Journal of Asian Earth Sciences 40(4): 883-895.

Eiby, G.A. 1966. The Modified Mercalli scale of earthquake intensity and its use in new Zealand. New Zealand Journal of Geology and Geophysics 9(1-2): 122-129.

Fekete, A. 2009. Validation of a social vulnerability index in context to river-floods in Germany. Natural Hazards and Earth System Sciences 9(2): 393-403.

Finch, C., C.T. Emrich, and S.L. Cutter. 2010. Disaster disparities and differential recovery in New Orleans. Population and Environment 31(4): 179-202.

Folk, C., S. Carpenter, T. Elmqvist, L. Gunderson, C.S. Holling, B. Walker, J. Bengtsson, K. Berkes, J. Colding, K. Danell, and M. Falkenmark. 2002. Resilience and development: Building adaptive capacity in a world of transformations. ICSU series on science for sustainable development: Resilience and sustainable development. Stockholm: International Council for Science.

Fu, B., P. Shi, H. Guo, S. Okuyama, Y. Ninomiya, and S. Wright. 2011. Surface deformation related to the 2008 Wenchuan earthquake, and mountain building of the Longmen Shan, Eastern Tibetan Plateau. Journal of Asian Earth Sciences 40(4): 805-824.

Gansu Provincial Bureau of Statistics. 2003. Gansu statistical yearbook. Beijing: China Statistics Press.

Gansu Provincial Bureau of Statistics. 2009. Gansu statistical yearbook. Beijing: China Statistics Press.

Gansu Provincial Bureau of Statistics. 2012. Gansu statistical yearbook. Beijing: China Statistics Press.

Gorum, T., X. Fan, C.J. van Westen, R.Q. Huang, Q. Xu, C. Tang, and G. Wang. 2011. Distribution pattern of earthquake-induced landslides triggered by the 12 May 2008 Wenchuan earthquake. Geomorphology 133(3-4): 152-167.

Guha-Sapir, D., R. Below, Ph. Hoyois. 2015. EM-DAT: The Centre for Research on the Epidemiology of Disasters/Office of U.S. Foreign Disaster Assistance (CRED/OFDA) International Disaster Database. Université Catholique de Louvain, Brussels, Belgium. http://www.emdat.be. Accessed 27 May 2015.

Guo, Y. 2012. Urban resilience in post-disaster reconstruction: Towards a resilient development in Sichuan, China. International Journal of Disaster Risk Science 3(1): 45-55.

Guo, D., and M. Hamada. 2013. Qualitative and quantitative analysis on landslide influential factors during Wenchuan earthquake: A case study in Wenchuan County. Engineering Geology 152(1): 202-209.

Hartigan, J.A., and M.A. Wong. 1979. A K-means clustering algorithm. Journal of the Royal Statistical Society. Series C (Applied Statistics) 28(1): 100-108.

Holling, C.S. 1996. Engineering resilience versus ecological resilience. In Engineering within ecological constraints, ed. P.C. Schulze, 31-44. Washington, DC: National Academy Press.

Klecka, W.R. 1980. Discriminant analysis. Quantitative applications in the social sciences series. Thousand Oaks, CA: Sage Publications.

Lam, N.S.N., H. Arenas, P.L. Brito, and K.B. Liu. 2014. Assessment of vulnerability and adaptive capacity to coastal hazards in the Caribbean Region. Journal of Coastal Research 70(sp1): 473-478.

Lam, N.S.N., H. Arenas, K. Pace, J. LeSage, and R. Campanella. 2012. Predictors of business return in New Orleans after Hurricane Katrina. PLoS ONE 7(10): e47935. doi: 10.1371/ journal.pone.0047935..

Lam, N.S.N., K. Pace, R. Campanella, J. Lesage, and H. Arenas. 2009. Business return in New Orleans: Decision making amid post-Katrina uncertainty. PLoS ONE 4(8): e6765. doi: 10.1371/ journal.pone. 0006765 .
Lam, N.S.N., Y. Qiang, H. Arenas, P. Brito, and K.B. Liu. 2015b. Mapping and assessing coastal resilience in the Caribbean Region. Cartography and Geographic Information Science 42(4): 315-322.

Lam, N.S.N., M. Reams, K. Li, C. Li, and L.P. Mata. 2015a. Measuring community resilience to coastal hazards along the Northern Gulf of Mexico. Natural Hazards Review 17(1): 04015013. doi: 10.1061/(ASCE)NH.1527-6996.0000193.

Li, K. 2011. Temporal changes of coastal community resilience in the Gulf of Mexico Region. Baton Rouge, Louisiana: Louisiana State University.

Li, C. 2013. Community resilience to coastal hazards: An analysis of two geographical scales in Louisiana. Baton Rouge, Louisiana: Louisiana State University.

Li, W., C.A. Airriess, A.C.-C. Chen, K.J. Leong, and V. Keith. 2010. Katrina and migration: Evacuation and return by African Americans and Vietnamese Americans in an Eastern New Orleans suburb. The Professional Geographer 62(1): 103-118.

Li, K., N.S.N. Lam, Y. Qiang, L. Zou, and H. Cai. 2005. A cyberinfrastructure for community resilience assessment and visualization. Cartographic and Geographic Information Science 42(sup1): 34-39.

Li, X., L. Wang, and S. Liu. 2016. Geographical analysis of seismic hazard resilience in Southwest China. International Journal of Disaster Risk Science 7(3): 257-276.

Li, H., H. Wang, Z. Xu, J. Si, J. Pei, T. Li, Y. Huang, S. Song, L. Kuo, Z. Sun, M.-L. Chevalier, and D. Liu. 2013. Characteristics of the fault-related rocks, fault zones and the principal slip zone in the Wenchuan Earthquake Fault Scientific Drilling Project Hole-1 (WFSD-1). Tectonophysics 584(22 January): 23-42.

Nalbant, S.S., and J. McCloskey. 2011. Stress evolution before and after the 2008 Wenchuan, China earthquake. Earth and Planetary Science Letters 307(1): 222-232.

National Bureau of Statistics of the People's Republic of China. 2001. Tabulation of the 2000 population census of the People's Republic of China. Beijing: China Statistics Press.

Nelson, E., G. Mendoza, J. Regetz, S. Polasky, H. Tallis, D. Cameron, K.M.A. Chan, G.C. Daily, J. Goldstein, P.M. Kareiva, E. Lonsdorf, R. Naidoo, T.H. Ricketts, and M. Shaw. 2009. Modelling multiple ecosystem services, biodiversity conservation, commodity production, and tradeoffs at landscape scales. Frontiers in Ecology and the Environment 7(1): 4-11.

NOAA (U.S. National Oceanographic and Atmospheric Administration). National Climate Data Center database. 2015. https:// www.ncdc.noaa.gov/data-access. Accessed 27 May 2015.

Norris, F.H., S.P. Stevens, B. Pfefferbaum, K.F. Wyche, and R.L. Pfefferbaum. 2008. Community resilience as a metaphor, theory, set of capacities, and strategy for disaster readiness. American Journal of Community Psychology 41(1-2): 127-150.

NRC (National Research Council). 2012. Disaster resilience: A national imperative. Washington, DC: The National Academies Press.

Peduzzi, P., H. Dao, C. Herold, and F.Mouton. 2009. Assessing global exposure and vulnerability towards natural hazards: The disaster risk index. Natural Hazards and Earth Systems Science 9(4): 1149-1159.

Perreault Jr, W.D., D.N. Behrman, and G.M. Armstrong. 1979. Alternative approaches for interpretation of multiple discriminant analysis in marketing research. Journal of Business Research 7(2): 151-173.

Ran, Y., W. Chen, X. Xu, L. Chen, H. Wang, C.-C. Yang, and S. Dong. 2013. Paleoseismic events and recurrence interval along the Beichuan-Yingxiu fault of Longmenshan fault zone, Yingxiu, Sichuan, China. Tectonophysics 584: 81-90.

Reams, M. A., N.S.N. Lam, and A. Baker. 2012. Measuring capacity for resilience among coastal counties of the U.S. Northern Gulf 
of Mexico Region. American Journal of Climate Change 1(4): 194-204.

Shaanxi Provincial Bureau of Statistics. 2003. Shaanxi statistical yearbook. Beijing: China Statistics Press.

Shaanxi Provincial Bureau of Statistics. 2009. Shaanxi statistical yearbook. Beijing: China Statistics Press.

Shaanxi Provincial Bureau of Statistics. 2012. Shaanxi statistical yearbook. Beijing: China Statistics Press.

Shan, B., X. Xiong, R. Wang, Y. Zheng, and S. Yang. 2013. Coulomb stress evolution along Xianshuihe-Xiaojiang fault system since 1713 and its interaction with Wenchuan earthquake, May 12, 2008. Earth and Planetary Science Letters 377-378: 199-210.

Shan, W. 2010. Comparing ethnic minorities and Han Chinese in China: Life satisfaction, economic well being and political attitudes. East Asian Policy 2(2): 13-22.

Sichuan Provincial Bureau of Statistics. 2003. Sichuan statistical yearbook. Beijing: China Statistics Press.

Sichuan Provincial Bureau of Statistics. 2009. Sichuan statistical yearbook. Beijing: China Statistics Press.

Sichuan Provincial Bureau of Statistics. 2012. Sichuan statistical yearbook. Beijing: China Statistics Press.

State Council of the People's Republic of China. 2010. Report on the work of the government. Beijing, China. http://www.gov.cn/ english/official/2010-03/15/content_1556124.htm. Accessed 27 May 2015.
Tang, C., J. Zhu, X. Qi, and J. Ding. 2011. Landslides induced by the Wenchuan earthquake and the subsequent strong rainfall event: A case study in the Beichuan area of China. Engineering Geology 122(1): 22-33.

Tang, C., J. Zhu, M. Chang, J. Ding, and X. Qi. 2012. An empiricalstatistical model for predicting debris-flow runout zones in the Wenchuan earthquake area. Quaternary International 250: 63-73.

Tate, E. 2012. Social vulnerability indices: A comparative assessment using uncertainty and sensitivity analysis. Natural Hazards 63(2): 325-347.

USGS (United States Geological Survey). 2008. Magnitude 7.9Eastern Sichuan, China. U.S. Geological Survey Earthquake Hazards Program. http://earthquake.usgs.gov/earthquakes/ eqinthenews/2008/us2008ryan/. Accessed 27 May 2015.

Xu, C., X. Xu, F. Dai, and A.K. Saraf. 2012. Comparison of different models for susceptibility mapping of earthquake triggered landslides related with the 2008 Wenchuan earthquake in China. Computers \& Geosciences 46: 317-329.

Zheng, G., S. Xu, S. Liang, P. Shi, and J. Zhao. 2013. Gas emission from the Qingzhu River after the 2008 Wenchuan earthquake, Southwest China. Chemical Geology 339: 187-193. 